This article was downloaded by: [The University of Manchester Library] On: 30 October 2012, At: 09:24

Publisher: Psychology Press

Informa Ltd Registered in England and Wales Registered Number: 1072954

Registered office: Mortimer House, 37-41 Mortimer Street, London W1T 3J H, UK

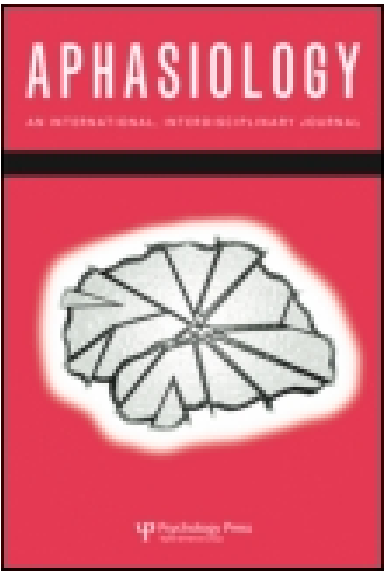

\title{
Aphasiology
}

Publication details, including instructions for authors and subscription information:

http:// www. tandfonline.com/loi/ paph20

\section{Case series, neuroscience-infused, computational neuropsychology will play a crucial role in the future of aphasiology. Commentary on Laine and Martin, "Cognitive neuropsychology has been, is, and will be significant to aphasiology"}

\author{
Matthew A. Lambon Ralph ${ }^{a} \&$ Paul Conroy ${ }^{a}$ \\ ${ }^{a}$ Neuroscience $\&$ Aphasia Research Unit (NARU), School of \\ Psychological Sciences, University of Manchester, Manchester, \\ UK \\ Version of record first published: 25 Oct 2012.
}

To cite this article: Matthew A. Lambon Ralph \& Paul Conroy (2012): Case series, neuroscienceinfused, computational neuropsychology will play a crucial role in the future of aphasiology. Commentary on Laine and Martin, "Cognitive neuropsychology has been, is, and will be significant to aphasiology", Aphasiology, 26:11, 1381-1386

To link to this article: http:// dx. doi.org/ 10.1080/ 02687038.2012.714942

Full terms and conditions of use: http://www.tandfonline.com/page/terms-andconditions

This article may be used for research, teaching, and private study purposes. Any substantial or systematic reproduction, redistribution, reselling, loan, sub-licensing, systematic supply, or distribution in any form to anyone is expressly forbidden.

The publisher does not give any warranty express or implied or make any representation that the contents will be complete or accurate or up to date. The accuracy of any instructions, formulae, and drug doses should be independently verified with primary sources. The publisher shall not be liable for any loss, actions, claims, proceedings, demand, or costs or damages whatsoever or howsoever caused 

material. 


\title{
Case series, neuroscience-infused, computational neuropsychology will play a crucial role in the future of aphasiology. Commentary on Laine and Martin, "Cognitive neuropsychology has been, is, and will be significant to aphasiology"
}

\author{
Matthew A. Lambon Ralph and Paul Conroy \\ Neuroscience \& Aphasia Research Unit (NARU), School of Psychological \\ Sciences, University of Manchester, Manchester, UK
}

In their target article, Laine and Martin (2012) summarise some of the crucial features and history of single case cognitive neuropsychology and its importance for the past and future of aphasiology. This is a timely topic for at least two reasons: First, it follows more general discussions on the role of single case versus case series approaches to neuropsychology (we refer the reader to these in-depth and thoughtful pieces, see Lambon Ralph, Moriarty, \& Sage, 2002; Lambon Ralph, Patterson, \& Plaut, 2011; Patterson \& Plaut, 2009; Schwartz \& Dell, 2011); second, Laine and Martin have brought the focus of the topic to aphasia more specifically. We consider this latter step to be an important one because it allows a discussion not only of the role of cognitive neuropsychology in understanding of the nature and neural basis of acquired language impairments, but also of improving the efficacy of the interventions we can offer patients with aphasia. Our brief commentary is therefore organised into two parts reflecting these dual themes.

\section{THE ROLE OF COGNITIVE NEUROPSYCHOLOGY IN UNDERSTANDING APHASIA}

Agreeing or disagreeing with the title of Laine and Martin's paper depends on how we define cognitive neuropsychology (CNP). If we restrict ourselves to a definition of CNP that solely involves the search for dissociations in single case studies without reference to computational and neural mechanisms, then we would argue that this form of CNP is of only limited benefit to aphasiology and, in fact, to neuropsychology and neuroscience more generally. This is, however, a straw man position-a good deal of contemporary CNP has "moved on", commonly using case series studies to explore the relationship between computationally derived mechanisms and overt patient behaviour (e.g., Dell, Schwartz, Martin, Saffran, \& Gagnon, 1997; Lambon Ralph, McClelland, Patterson, Galton, \& Hodges, 2001; Woollams, Lambon Ralph,

Address correspondence to: Professor M. A. Lambon Ralph, Neuroscience \& Aphasia Research Unit (NARU), School of Psychological Sciences (Zochonis Building), University of Manchester, Brunswick StreetManchester, M13 9PL, UK. E-mail: matt.lambon-ralph@manchester.ac.uk

This work was supported by MRC programme grants (G0501632 \& MR/J004146/1) to MALR.

(C) 2012 Psychology Press, an imprint of the Taylor \& Francis Group, an Informa business http://www.psypress.com/aphasiology

http://dx.doi.org/10.1080/02687038.2012.714942 
Plaut, \& Patterson, 2007), as well as folding in an increasing database about the neural underpinnings of normal and impaired language from functional and structural neuroimaging (Binder, Desai, Graves, \& Conant, 2009; Price, 2012; Saur et al., 2008). This form of contemporary CNP provides a rich smorgasbord, and we believe aphasiology would benefit significantly by feasting at this exciting buffet.

A good proportion of Laine and Martin's target article is devoted to discussing the pros and cons of single case CNP. There is no doubt that single case reports and the theories that have arisen from them, have played a crucial role in the formation and evolution of both CNP and aphasiology. Indeed, the power of single case studies has been such that it is easy to forget that famous ones, like the amnesic patient HM, were actually originally reported as a part of a case series (Scoville \& Milner, 1957). Single case studies have advanced theory and clinical practice primarily through the demonstration of a behavioural dissociation or, more powerfully, a double dissociation. As noted by Laine and Martin, such behavioural dissociations can reflect the presence of neurally separable cognitive or language sub-components crucial to a task (e.g., semantic vs phonological components of speech production). It is important to note, however, that other factors can also explain the presence of behavioural dissociations, especially when they are not "classic" double dissociations (Shallice, 1988). Past authors have described the various factors that might generate a dissociationincluding differential assessment sensitivity, unmatched stimuli, individual differences, non-linear severity-behaviour functions, etc. - and we refer the reader to these discussions (Lambon Ralph et al., 2002; Patterson \& Plaut, 2009; Schwartz \& Dell, 2011; Shallice, 1988). The crucial issue for the present discussion is that, through single case studies alone, it can be hard if not impossible to establish the source(s) of the observed dissociation.

Many of the most well-known and influential single case studies (e.g., GR - deep dyslexia; JBR - category-specific deficits; WLP - separation of syntax and semantics: Marshall \& Newcombe, 1973; Schwartz, Marin, \& Saffran, 1979; Warrington \& Shallice, 1984) became more than one-off clinical trinkets because they were followed by reports of other patients with similar or contrasting behavioural dissociations (Capitani, Laiacopna, Mahon, \& Caramazza, 2003; Coltheart, Patterson, \& Marshall, 1980; Hodges, Patterson, Oxbury, \& Funnell, 1992). Laine and Martin, in Footnote 1, note the metaphorical single case study of the talking pig, and this offers the same observations as those noted above. The talking pig by itself is not surprising unless it is compared against all of the other non-talking typical pigs (if a single alien appeared and could talk, we would not know if this feature was typical without meeting other aliens of the same type) and, more importantly, the crucial scientific advances that a talking pig could bring (in understanding the anatomical, neural, and genetic factors underpinning speech and language) would only be made apparent (a) by direct comparisons against other non-talking pigs and (b) through replication, by inducing the same genetic transformation (i.e., building a case series).

Although case series and comparative case series studies are admittedly more logistically challenging (in terms of the amount of testing and recruitment required), they do bring many advantages over single case studies alone. The case series design preserves the detail of the single case investigation but also inherits the ability to measure inter-participant variations like a group study. This means that it is possible (a) to confirm the level of consistency across individual patient profiles within a series (behaviour and underlying lesions) while (b) demonstrating meaningful and reliable differences between groups. Indeed, we have found the comparative case series methodology to be a particularly useful one for exploring contrastive impairments 
(e.g., within semantic cognition: Jefferies \& Lambon Ralph, 2006; Lambon Ralph, Ehsan, Baker, \& Rogers, 2012; Lambon Ralph, Lowe, \& Rogers, 2007) but also for investigating the reliability of therapy interventions (see below, and Lambon Ralph, Snell, Fillingham, Conroy, \& Sage, 2010). A second observation to make is the following: any theory that aspires to describe the cognitive machinery underpinning language functions, and thus the necessary interventions to ameliorate the effects of damage to these computational components, has to make predictions in the form of an association (Lambon Ralph et al., 2002; Lambon Ralph, Patterson, et al., 2011). This holds irrespective of the type of computational model described or implementedif component/process $\mathrm{A}$ is purported to be crucial to language task $\mathrm{X}$, one would then expect to find that differential levels of damage to A will covary, linearly or nonlinearly, with performance on X. Such functional associations cannot be tested or plotted out, by definition, using a datum (single case study) but require data (a case series investigation).

Our final note in this first section of our commentary relates to the importance of recovery in understanding and treating aphasia. Much of aphasiological investigation and theory is based on the study of patients in the chronic phase when much, if not all, of the spontaneous recovery phase has passed. In addition, some researchers apply the neuropsychological notion of "subtractivity" (Caramazza \& McCloskey, 1988; Ellis \& Young, 1988; Shallice, 1988) by which it is assumed that the patient's behavioural presentation reflects the normal language systems minus the impaired components (i.e., without substantial reworking of pre-existing or novel neural systems for language). Although a convenient simplifying assumption, this approach has the danger of overlooking crucial insights that could be gleaned by studying patients during spontaneous recovery which can last for up to a year or more post onset (i.e., reflecting neuroplasticity that lasts beyond the period of acute oedema and other transient physiological reactions). In some recent work we have used computational models to simulate these variable recovery profiles (using the models' learning algorithms to re-optimise the remaining-undamaged-computational resources) and to explore how some dissociations can be formed or enhanced through the recovery processes themselves (Keidel, Wellbourne, \& Lambon Ralph, 2010; Ueno, Saito, Rogers, \& Lambon Ralph, 2011; Welbourne \& Lambon Ralph, 2007; Welbourne, Woollams, Crisp, \& Lambon Ralph, 2011). Most importantly, if we could understand the changing mechanisms during spontaneous recovery across patients then we might be in a much stronger position to define, measure, and improve interventions for aphasia (Welbourne \& Lambon Ralph, 2007).

\section{THE ROLE OF COGNITIVE NEUROPSYCHOLOGY IN IMPROVING INTERVENTIONS FOR APHASIA}

As noted in the opening of this commentary, we consider case series cognitive neuropsychology to be important not only for aphasiological theory but also for improving our understanding and efficacy of language interventions. For convenience we have divided our commentary into sections on theory and practice but we should note at the outset that we consider the two to be symbiotically related: not only does theory inform practice, but also interventions can be used as tests of a theory (e.g., Lambon Ralph, Hesketh, \& Sage, 2004). For example, if a theory suggests that faulty component A underpins patients' poor ability on task X, then intervention can potentially be used as a test of the causality between A and X; following successful treatment 
of $\mathrm{A}$ and its reconnection to the rest of the language machinery, one should observe improvement in ability on task X.

Laine and Martin note the criticism that CNP — in its box-and-arrow guise - has done little to inform us about how to treat a patient's language impairment. We would argue that this is due, in part, to the reliance on the boxes and arrows rather than CNP per se. Two major observations are noteworthy here: First, the box-and-arrow singlecase-study form of CNP gives some information about how sub-components within the language system might dissociate, but it tells us little about the computations supported within and between neural components. Contemporary, neuroscience-imbued CNP is much better placed to consider and test the neurocomputational basis of language function and impairments - and this has to be a better starting point for considering interventions. After all, knowing about the function and connectivity of parts within a car engine is much more helpful when diagnosing and undertaking car repairs than simply knowing about the layout of the engine per se. Second, the pursuit of ever more finely detailed box-and-arrows frameworks is facilitated by the selection and study of patients with (apparently) hyper-selective deficits. Although very striking when they are found in the clinic, these individual cases are rare and are unrepresentative of most patients, who have multiple language and non-language (perceptual and/or cognitive) deficits of differing severities. In contrast, computational CNP emphasises how each component might function at different severity levels, how it interacts with and is partially compensated by other language and cognitive elements (Ueno et al., 2011; Welbourne et al., 2011). This seems a more useful contribution for CNP to make to therapy planning which, when taken alongside social and environmental factors, can be used to formulate holistic interventions for the majority of patients.

To conclude we should note the potential power of case series CNP not only to aphasiological theory but also to explorations of therapy efficacy. As noted above, the assembly of a patient case series licenses an exploration of the link between observed impairments and damage to underlying mechanisms - including investigation of how damage severity relates to resultant language impairment (which can often be non-linear: e.g., Lambon Ralph et al., 2001; Schwartz, Dell, Martin, Gahl, \& Sobel, 2006). The same approach extends to relating the outcome of language interventions to the underlying pattern of impairments across patients. Thus, for example, it becomes possible to explore how the efficacy of a certain intervention changes according to the severity of an underlying core deficit (e.g., degree of phonological impairment), or in the context of multiple varying deficits (e.g., different degrees of phonological and semantic impairment), or when language impairments co-occur with non-language, cognitive deficits. Undertaking case series language interventions are even more logistically challenging than aphasiological studies, because in-depth background aphasiological testing has to be combined with consistent, multi-session intervention. Some recent studies have managed to construct case series intervention studies to reveal expected and unexpected findings. For example, in the domain of treatment for word-finding difficulties two independent studies have found that severity of both language (primarily phonological) and cognitive impairments predicts therapy outcome (Lambon Ralph et al., 2010; van de Sandt-Koenderman et al., 2008). Such studies indicate that, as expected, language and cognitive impairments are independent yet the presence of both deficits reduces the efficacy of naming interventions, and thus that both aspects of higher cortical function need to be considered when planning therapy. 
In conclusion, our understanding of aphasiological theory and intervention is significantly advanced by contemporary CNP - especially when studies utilise comparative case series designs and explore computational hypotheses through implemented models. Given the rise of ever-increasingly sophisticated functional and structural neuroimaging, we also expect that computational, case series CNP will be augmented even further by an enhanced understanding of the pattern of lesions to the cortical and white-matter pathways that underpin the language neural network (Bates et al., 2003; Saur et al., 2008). This will be especially so if these neuroscience observations can be fused with computational accounts of normal and impaired language function (e.g., Ueno et al., 2011).

\section{REFERENCES}

Bates, E., Wilson, S. M., Saygin, A. P., Dick, F., Sereno, M. I., Knight, R. T., \& Dronkers, N. (2003). Voxel-based lesion-symptom mapping. Nature Neuroscience, 6, 448-449.

Binder, J. R., Desai, R. H., Graves, W. W., \& Conant, L. L. (2009). Where is the semantic system? A critical review and meta-analysis of 120 functional neuroimaging studies. Cerebral Cortex, 19, 2767-2796.

Capitani, E., Laiacona, M., Mahon, B., \& Caramazza, A. (2003). What are the facts of semantic categoryspecific deficits? A critical review of the clinical evidence. Cognitive Neuropsychology, 20, 213-261.

Caramazza, A., \& McCloskey, M. (1988). The case for single-patient studies. [Special issue: Methodological problems in cognitive neuropsychology.] Cognitive Neuropsychology, 5, 517-527.

Coltheart, M., Patterson, K., \& Marshall, J. C. (1980). Deep dyslexia. London: Routledge \& Kegan Paul.

Dell, G. S., Schwartz, M. F., Martin, N., Saffran, E. M., \& Gagnon, D. A. (1997). Lexical access in aphasic and nonaphasic speakers. Psychological Review, 104, 801-838.

Ellis, A. W., \& Young, A. W. (1988). Human cognitive neuropsychology. London: Lawrence Erlbaum Associates Ltd.

Hodges, J. R., Patterson, K., Oxbury, S., \& Funnell, E. (1992). Semantic dementia: Progressive fluent aphasia with temporal lobe atrophy. Brain, 115, 1783-1806.

Jefferies, E., \& Lambon Ralph, M. A. (2006). Semantic impairment in stroke aphasia vs. semantic dementia: A case series comparison. Brain, 129, 2132-2147.

Keidel, J. L., Welbourne, S. R., \& Lambon Ralph, M. A. (2010). Solving the paradox of the equipotential and modular brain: A neurocomputational model of stroke vs. slow-growing glioma. Neuropsychologia, 48, 1716-1724.

Laine, M., \& Martin, N. (2012). Cognitive neuropsychology has been, is, and will be significant to aphasiology. Aphasiology, 26, 1362-1376.

Lambon Ralph, M. A., Ehsan, S., Baker, G. A., \& Rogers, T. T. (2012). Semantic memory is impaired in patients with unilateral anterior temporal lobe resection for temporal lobe epilepsy. Brain, 135, 242-258.

Lambon Ralph, M. A., Hesketh, A., \& Sage, K. (2004). Implicit recognition in pure alexia: The Saffran effect - A tale of two systems or two procedures? Cognitive Neuropsychology, 21, 401-421.

Lambon Ralph, M. A., Lowe, C., \& Rogers, T. T. (2007). Neural basis of category-specific semantic deficits for living things: Evidence from semantic dementia, HSVE and a neural network model. Brain, 130, 1127-1137.

Lambon Ralph, M. A., McClelland, J. L., Patterson, K., Galton, C. J., \& Hodges, J. R. (2001). No right to speak? The relationship between object naming and semantic impairment: Neuropsychological evidence and a computational model. Journal of Cognitive Neuroscience, 13, 341-356.

Lambon Ralph, M. A., Moriarty, L., \& Sage, K. (2002). Anomia is simply a reflection of semantic and phonological impairments: Evidence from a case series study. Aphasiology, 16, 56-82.

Lambon Ralph, M. A., Patterson, K., \& Plaut, D. C. (2011). Finite case series or infinite single-case studies? Comments on "Case series investigations in cognitive neuropsychology" by Schwartz and Dell (2010). Cognitive Neuropsychology, 28, 466-474. doi:10.1080/02643294.2012.671765

Lambon Ralph, M. A., Snell, C., Fillingham, J. K., Conroy, P., \& Sage, K. (2010). Predicting the outcome of anomia therapy for people with aphasia post CVA: Both language and cognitive status are key predictors. Neuropsychological Rehabilitation, 20, 289-305.

Marshall, J. C., \& Newcombe, F. (1973). Patterns of paralexia: A psycholinguistic approach. Journal of Psycholinguistic Research, 1, 175-199.

Patterson, K., \& Plaut, D. (2009). "Shallow draughts intoxicate the brain": Lessons from cognitive science for cognitive neuropsychology. Topics in Cognitive Science, 1, 39-58. 
Price, C. J. (2012). A review and synthesis of the first 20 years of PET and fMRI studies of heard speech, spoken language and reading. NeuroImage, 62, 816-847.

Saur, D., Kreher, B. W., Schnell, S., Kümmerer, D., Kellmeyer, P., Vry, M-S., . . . Weiller, C. (2008). Ventral and dorsal pathways for language. Proceedings of the National Academy of Sciences, 105, 18035-18040.

Schwartz, M. F., \& Dell, G. S. (2011). Case series investigations in cognitive neuropsychology. Cognitive Neuropsychology, 27, 477-494.

Schwartz, M. F., Dell, G. S., Martin, N., Gahl, S., \& Sobel, P. (2006). A case series test of the interactive two-step model of lexical access: Evidence from picture naming. Journal of Memory and Language, 54, 228-264.

Schwartz, M. F., Marin, O. S. M., \& Saffran, E. M. (1979). Dissociations of language function in dementia: A case study. Brain and Language, 7, 277-306.

Scoville, W. B., \& Milner, B. (1957). Loss of recent memory after bilateral hippocampal lesions. Journal of Neurology, Neurosurgery \& Psychiatry, 20, 11-21.

Shallice, T. (1988). From neuropsychology to mental structure. Cambridge, UK: Cambridge University Press.

Ueno, T., Saito, S., Rogers, T. T., \& Lambon Ralph, M. A. (2011). Lichtheim 2: Synthesizing aphasia and the neural basis of language in a neurocomputational model of the dual dorsal-ventral language pathways. Neuron, 72, 385-396.

van de Sandt-Koenderman, W. M. E., van Harskamp, F., Duivenvoorden, H. J., Remerie, S. C., van der Voort-Klees, Y. A., Wielaert, S. M., et al. (2008). MAAS (Multi-Axial Aphasia System): Realistic goal setting in aphasia rehabilitation. International Journal of Rehabilitation Research, 31, 314-320.

Warrington, E. K., \& Shallice, T. (1984). Category specific semantic impairments. Brain, 107, 829-854.

Welbourne, S. R., \& Lambon Ralph, M. A. (2007). Using PDP models to simulate phonological dyslexia: The key role of plasticity-related recovery. Journal of Cognitive Neuroscience, 19, 1125-1139.

Welbourne, S. R., Woollams, A. M., Crisp, J., \& Lambon Ralph, M. A. (2011). The role of plasticity-related functional reorganization in the explanation of central dyslexias. Cognitive Neuropsychology, 28, 65-108.

Woollams, A. M., Lambon Ralph, M. A., Plaut, D. C., \& Patterson, K. (2007). SD-squared: On the association between semantic dementia and surface dyslexia. Psychological Review, 114, 316-339.

\title{
Clinical aphasiology and CNP: A pragmatic alliance. Commentary on Laine and Martin, "Cognitive neuropsychology has been, is, and will be significant to aphasiology"
}

\author{
Anne Whitworth ${ }^{1}$, Janet Webster ${ }^{2}$, and David Howard ${ }^{2}$ \\ ${ }^{1}$ School of Psychology and Speech Pathology, Curtin Health Innovation Research \\ Institute, Curtin University, Perth, Australia \\ ${ }^{2}$ Speech and Language Sciences, Newcastle University, Newcastle upon Tyne, UK
}

Clinical aphasiologists embraced cognitive neuropsychology (CNP) models soon after CNP emerged as a discipline in the 1970s, recognising the limitations on which the models were based while simultaneously valuing their contribution to clinical diagnosis and treatment, and building on these limitations through refining the methodology and approaches to address them. Driven by an obligation to look for

Address correspondence to: Anne Whitworth, School of Psychology and Speech Pathology, Curtin University, GPO Box U1987, Perth, Western Australia. E-mail: anne.whitworth@curtin.edu.au

(C) 2012 Psychology Press, an imprint of the Taylor \& Francis Group, an Informa business http://www.psypress.com/aphasiology

http://dx.doi.org/10.1080/02687038.2012.714946 